\title{
On the eve of tomorrow
}

\author{
Enikő Korcsmáros ${ }^{1}$, Bence Csinger ${ }^{2 *}$ \\ ${ }^{1}$ UJS Faculty of Economics and Informatics, Department of Economics, P.O.Box. 54, Komárno, \\ Slovakia \\ ${ }^{2}$ UJS, Faculty of Economics and Informatics, MSC student
}

\begin{abstract}
The main purpose of our research is to examine the role of social media in the marketing strategy of small and medium-sized enterprises. The reason for our choice of topic is that social media is extremely important nowadays, which also influences the marketing strategy of the sector under investigation. For this reason, we examined the relevance of this topic in the Central and Western Transdanubian region. In the first part of our research, we collacted information on social media concepts and their distribution internationally and domestically. As a next step, we focused on presenting the most common social media and the opportunities they offer. Then we provide an insight of the situation of the regions under study, and the author's hypotheses are formulated, followed by an examination of their relevance.
\end{abstract}

\section{Introduction}

Our research aims to examine the role of social media in the marketing strategy of small and medium-sized enterprises with the help of domestic and foreign literature.The significance and topicality of this topic is given by the fact that the role of social media has greatly increased in relation to the sector we are examining.The aim of the research is to provide the reader with an insight into the appreciation of the role of social media in the marketing strategy of small and medium-sized enterprises, especially in relation to the two regions of Hungary.Our research covers the Western Transdanubia region and the Central Transdanubia region.Our choice of this topic was also influenced by the answer to the question of how well companies operating in the small and medium-sized enterprise sector are aware of the opportunities provided by social media today and how much they use these opportunities to create or increase a competitive advantage.In our dissertation, we place great emphasis on the role of social media within the marketing strategy of small and medium enterprises.As a first step, our goal is to introduce the ever-changing, renewable conceptual definitions of social media.After that, with the help of secondary research, we provide a comprehensive picture of their development and spread, both internationally and domestically.Each of the social media that is most popular in the world today is presented.

${ }^{*}$ Corresponding author: csinger.bence@gmail.com 
In the following chapters of our theoretical review, the authors provide an insight into the opportunities provided by social media and their situation today. With the help of primary data collection, we conducted a regional study of the two regions of Hungary.Our research covers the Western Transdanubia region and the Central Hungary region. Finally, we conducted a comparative analysis of the two regions we examined, as a result of which we would like to provide an insight into the importance and appreciation of the role of social media. As a result, the research goal of our dissertation is to provide a comprehensive picture of the situation of the topic we are examining and the opportunities it offers in the Western Transdanubia and Central Transdanubia region.

\section{Domestic and international guidelines of the topic}

In the conceptual definition of social media, the chapter presents to the reader the path of the development and spread of the researched topic in an international and domestic context. This is followed by an introduction to the most widespread social media and the opportunities they offer and their importance in today's world.

\subsection{The path of social media development}

As a first step in our research, we examine the conceptual definitions of social media:"Social media, or the commonly used English term" social media ', ["] is a set of media that users fill with content. Anyone can participate in social media, as it is a community where users engage in open dialogue with each other without control, mainly for the purpose of connecting. " [1]

Social media has been specifically developed to fill this online interface exclusively with users with content that they can connect with each other, thus generating additional content. Another advantage is that it is free for customers and cost-effective on the corporate side [1]. The path of its formation can be divided into five parts: Web 1.0, Web 2.0, Web 3.0, Web 4.0 and Web 5.0.

In Hungary, it can be said that social media appeared with a significant time lag. The first truly successful website was the iWiW platform created by Média és Kommunikációs Zrt., Which started operating on April 14, 2002. The name refers to the abbreviation International who is who. After almost 4 years, the website was acquired by Magyar Telekom in April 2006. As a result of the implementation, numerous new features have emerged. These include, for example, the fact that individual users receive e-mail notifications about messages and mark-ups on the platform, which has led to a significant increase in the number of new user registrations.Meanwhile, iViW's number one competitor, myVIP, appeared on the market in 2006. The uniqueness of the site was given by the fact that in addition to allowing the creation of different communities and groups, its users had an unlimited number of invitations, as well as permission to upload any number of images and videos. In addition, two other social media platforms are worth mentioning. The first is none other than baratikor.com, which, although it started operating in Latvia in 2004, became available to Hungary by 2006. Although the leaders did not place much emphasis on the Hungarian market, the services of this website were the cornerstone of Facebook. The second social site worth mentioning is mutasd.be, which started with really innovative solutions. Facebook, known today as the best-known social website, appeared in Hungary in 2007, but until October 2010, iWiW was the most popular social platform. After 2010, the website, which has been constantly evolving since its launch, has taken over in terms of traffic and number of users [2].. 


\subsection{The most widespread social media and the opportunities they offer}

The next step is to review the most common social media today. The beginning of the history of Facebook can be traced back to February 2004. This year, the four founding members, Mark Zuckerber, Dustin Moskovitz, Chris Hughes and Eduardo Saverin, created a community platform that was still known as "thefacebook". Its expansion was extremely rapid. In March of the year of its foundation, it was launched on three more campuses (Yale, Columbia, Stanford), and a year later, 800 campuses already used the site, as the message board function was introduced by the founders.Its uniqueness was further enhanced by the fact that after a year the "mobile version" was also released, so the service became available to almost everyone. The year 2009 can also be considered as a turning point, as the so-called "like" function was introduced at that time [3].

Currently, the number of active users per month reaches 2.38 billion and it has 1.56 billion active users per day [4].

The beginning of Twitter's history can be traced back to 2006, when four friends, Jack Dorsey, Noah Glass, Evan Williams, and Biz Stone, sought answers to the question of how to create a kind of community mini-blog. Initially, the platform provoked extreme dissatisfaction. It was only through luck, namely a conference held in Texas in 2007, that the company "escaped" where guests could communicate with each other and organize their programs exclusively through Twitter messages. Despite the initial difficulties, what made the website really great and unique was that it became popular in political circles, which is still true today. As a result, Twitter has now grown into one of the most popular social platforms [5].

Instagram, as one of the most popular platforms today, started operating in October 2010 on Apple-sold iPhones. The app was created by Kevin Systrom and Mike Krieger. Its popularity has been and continues to be due to its simplicity as well as the uniqueness of its creative photographs. The service will be available on Android devices from April 2012 and on Windows Phone devices from November 2013. Its development can be said to be unbroken, with the update of the new version released on the market in 2013, each user has the opportunity to make a video of up to one minute, to which the user can add captions, location tags and sharing pages like Instagram [6].

Currently, the number of people who actively use Instagram is more than 1 billion per month, nearly half of whom are daily active users. With regard to the companies present on the platform, it can be said that more than 25 million companies have a company profile, which shows a constantly growing trend [7].

LinkedIn, the largest business social network in the social media market, was founded on May 5, 2003 by Allen Blue, Konstantin Guericke, Eric Ly, and Jean-Luc Vaillant. The company has now become the biggest dream of startups, and has played and continues to play a major role in the emergence of professional life paths on social media platforms. Compared to previous founders, the primary goal of the founders of LinkedIn was to show people new opportunities to do business. In ten years, it has grown into an international company with more than 3,700 employees $[8,9]$. The company currently has 590 million users, half of whom are active monthly users [9].

The importance of social media in business is growing at an extremely rapid rate. By having a business brand present on these websites, it generates and realizes more business, and is able to satisfy the needs of customers at a higher level, thanks to which it facilitates the company's own digital marketing activities. It is vital for companies to take advantage of websites like Facebook, Twitter, Instagram, LinkedIn in case they want to stay competitive or just build an advantage over their competitors. The next step is to examine the importance of social media in business by analyzing their benefits. The first notable benefit is the promotion of community advertising. As more and more businesses experiment with digital advertising, they are realizing that this type of strategy has 
enormous benefits. These include the fact that advertising costs are significantly low, the target audience is targeted, and performance analysis is real-time, meaning that the company is able to continuously monitor the performance of its advertising. The next big benefit of social media is that it proves to be an effective tool to increase brand awareness. At the same time, communication is an important aspect, as social media is about building conversations. In addition, it is important that their goal be to establish two-way communication [10].

In terms of social media, Hungary is characterized by two important figures. Based on the NRC's research, it can be said that $84 \%$ of Hungarian Internet users use the Internet every month, while $73 \%$ use the Internet every day, of course in different proportions by age group. The proportion of Internet users in the 15-34 age group is almost $100 \%$, while the over-50 age group is significantly behind. Furthermore, the research prepared for NMHH shows that the average time spent in Hungary is 3.8 hours per day. $97 \%$ of users are considered active social media users, and in terms of popularity, Facebook is the leader with $89 \%[11,12]$.

Currently, social media itself is the most significant marketing communication tool. The reason for this is that companies and users have the opportunity to use a large amount of social platforms where two-way communication is dominant. From a corporate point of view, it can be said that having a presence on each platform is more cost-effective, all marketing tools are available [11].

The next step is to examine the importance of social media in business by analyzing their benefits. The first notable benefit is the promotion of community advertising. As more and more businesses experiment with digital advertising, they are realizing that this type of advertising strategy has enormous benefits. These include significantly lower advertising costs, targeted audience reach, and real-time performance analysis, meaning you can continuously monitor your ad performance. The next big benefit of social media is that it proves to be an effective tool to increase brand awareness. But what tasks can be done to accomplish this step? The number one activity is that a given company needs to find its target audience.In addition, it is a key step to make the content it creates spectacular. At the same time, communication is important, as social media is about building conversations. However, it is important that their goal be to establish two-way communication [10].

The goals of a company's well-designed marketing campaigns will only be successful if its strategy focuses on triggering activity. By this we mean the process by which each user responds to a company listing, for example by posting or sharing. This is necessary because, on the one hand, it is the basis of the conversion, i.e., the consumer most often buys online by contacting the brand in advance, and on the other hand, the algorithms of each platform support content that encourages consumers to be active. Sweepstakes, polls and competitions, for example, make a major contribution to this.So-called influencers, who are popular online personalities today with a large number of followers, can be of great help in the stimulation. If the target audience of the company and the selected influencer coincide, then the mediated marketing message can be successful. A key factor is also for the company to offer a "story" to its consumers, as in today's world, the emphasis is on human relationships. However, if the company is able to transfer this kind of interaction and content to a branded environment, it can become a market leader.Most people would like to see posts related to various promotions or videos about a new product / service that are funny or instructive. While compliance may seem like a difficult task, if a business is able to weave a story into its strategy, it will meet these criteria [7]. 


\section{The aim of the dissertation}

The main goal of our research is to provide insight into the role of social media within the marketing strategy of small and medium enterprises. The choice of topic is related to the interest of the SME sector in the marketing strategy, the knowledge gained so far, and the relatively large amount of used literature. In our research, we would like to point out the important role of social media as a marketing communication tool in the life of small and public enterprises, and what opportunities it provides for them in terms of positive development.The aim of the dissertation is to provide the reader with a comprehensive picture of the role of social media in the marketing strategy of small and medium-sized enterprises by examining two regions of Hungary, Central Transdanubia and Western Transdanubia. With regard to research, the following sub-objectives can be formulated:

- Overview of the development path of social media in domestic and international context.

- Presentation of the four most common social media today

- Explain the benefits of social media.

- Examination of the current situation of the Western Transdanubia and Central Transdanubia regions from an economic point of view.

- Presentation of the economic situation of the studied regions by means of primary data collection.

- Examination of the correctness of the formulated hypotheses.

With the aim of achieving the main goal of the dissertation, five hypotheses were formulated in connection with the examined problem. The answers obtained during our primary data collection, which were made possible by the application of a quantitative, questionnaire method in the studied regions, greatly contribute to the achievement of our goals. With the help of these data, the authors highlight the appreciation of the role and importance of social media in Hungary as well. Finally, we aim to make proposals based on research plans that SMEs can fully turn to their own advantage.

\section{Research methodology and method}

In conducting their research, the authors examined the role of social media in the marketing strategy of small and medium-sized enterprises. As a first step, a research plan was developed, which included the method of examining the SME sector in the research topic, and the individual hypotheses were formulated. As a first step, the development, spread and role of social media in relation to enterprises were presented with the help of domestic and international literature. To perform our practical research, we performed primary data collection. The query lasted from November 2019 to February 2020, and the implementation was implemented with a direct mail strategy. With the help of a questionnaire, we examined the small and medium-sized enterprise sector for the two regions of Hungary. In the first part of our method of quantitative analysis, we were primarily interested in demographic data. We then looked for answers as to exactly what the company uses social media for, which website is most important to it, how important it is for it to be present on the platforms mentioned earlier, and whether they monitor their competitors in this regard.In the third part of our questionnaire research, we placed great emphasis on getting the reader an answer to the question of what percentage of their marketing activities and marketing costs are spent on social media presence and future plans. As the next step of our research plan, we examined the Western Hungary and the Central Transdanubia regions separately with the help of secondary data collection. As a final step, the evaluation process 
followed, in which we compared the information obtained during the primary and secondary data collection and performed a regional study for the two regions.In the processing of secondary data, the applied analysis methods were divided into groups of basically simple descriptive statistical methods and methods that allowed deeper statistical data analysis. The PSPP program we used was a great help to us in the evaluation process. During the examination of the formulated hypotheses, we used descriptive statistical methods, and within that, our assumptions were analyzed with the help of cross-tabulation analyzes.A significance level of 5\% was determined during the evaluation. In the analysis of each variable, we performed a Chi-square test, within which Pearson's Chi-square Asym was taken into account. sig value, with the help of which we determined that the null hypothesis or the alternative hypothesis will be accepted taking into account the specified $5 \%$ significance level.

\section{Research results}

The chapter provides the reader with an insight into the importance of the role of social media for the two regions of Hungary through our primary data collection. The regions under study and the fact that our hypotheses are correct or not are presented.

\subsection{Analysis of questionnaire query data}

During our primary data collection, we conducted a questionnaire survey on the presence of small and medium-sized enterprises operating in the Western and Central Transdanubia region in social media. Our questionnaire contained 27 questions that covered not only the general characteristics of each company but also the importance and future of the role of social media. In the course of our study, 591 responses were returned and processed from the 3,000 questionnaires sent out, of which $61.1 \%$ came from the Western Transdanubia region and $38.9 \%$ from the Central Transdanubia region.In terms of the number of employees, it can be said that in the Central Transdanubia region $70 \%$ of the respondents are micro enterprises, $21.4 \%$ are small enterprises and $8.6 \%$ are medium-sized enterprises. According to the nature of the activity, it can be stated that the majority of micro, small and medium-sized enterprises operate in the service sector, followed by the commercial sector and then the manufacturing sector.Similar results were obtained in the Western Transdanubia region. $72.1 \%$ of businesses have more than 10 years of professional experience in the market. After analyzing the general characteristics, we move on to questions related to our research topic. Surprisingly, we found that $23.6 \%$ of the companies surveyed are not present on any social media platform. Graph 1 illustrates well the proportion of companies using each social media platform in terms of headcount. The size distribution of companies is shaped by favoring Facebook in all categories, followed by Twitter with the exception of medium-sized businesses. Nowadays, in the case of Instagram, which is popular among individual users, it is said that micro-enterprises use it most often in terms of the number of employees, and in connection with LinkedIn, it is clear that medium-sized enterprises prefer it to small enterprises. 


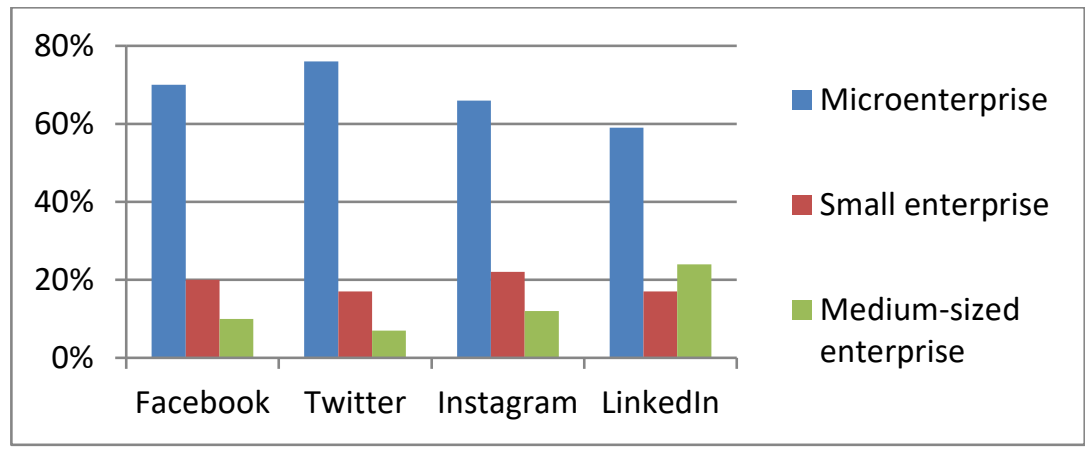

Fig. 1: Distribution of presence on each community platform in terms of size of enterprises

Our questionnaire shows that the primary goal for micro-enterprises is to build brand awareness, provide information and increase the number of target audiences. In the case of small businesses, this is as follows: building brand awareness for them and providing information is the primary mission, which is similar for medium-sized businesses. Breaking into new markets, creating a competitive advantage and increasing revenues are more important for micro-enterprises.In the next question, we were looking for the answer to whether companies employ a separate person, individuals, an outside company who deals with presence on social media. In this respect, $72.9 \%$ of firms answered in the negative and only $16.6 \%$ of them employ regularly. This is surprising as they do not put enough energy into social media presence based on this. Without the help of a person who does not specialize in this, they will not be able to reap the benefits of social media platforms.An important question in our research was the importance of presence in social media. The average value of all responses is 3.8 , which means that the presence on each platform usually plays an important role for businesses. In our view, the value is not higher because organizations are only aware of a few benefits and do not have a comprehensive picture of how profitable this step can be for them overall and in the long run. When asked what percentage of their marketing activities and marketing costs their presence on social media accounted for, the largest number of respondents in the surveyed sector was only $0-25 \%$, which is surprising as they suggest that they are probably unaware of social media opportunities..Graph 2 shows a comparison of the marketing costs of small and mediumsized enterprises and the distribution of enterprises by size, based on which it can be said that micro-enterprises spend the largest percentage of their marketing costs on social media presence. They are followed by small businesses and finally medium-sized businesses.

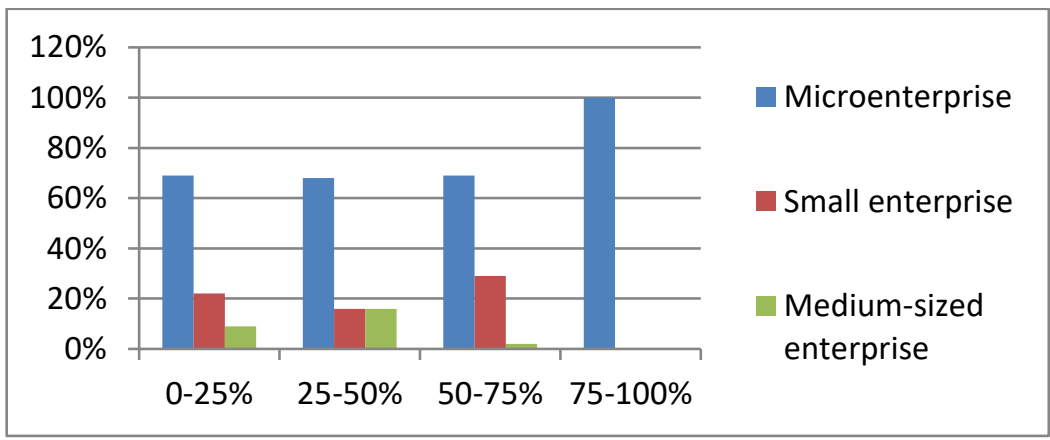

Fig. 2: Comparison of marketing costs by SME group 
We then wondered whether there was a change in the lives of individual companies using the platforms mentioned earlier and, if so, in what direction. Only $0.7 \%$ of respondents felt the negative impact of this, $35.2 \%$ said there was no change, and $64.2 \%$ said it brought a clear positive change in the life of their company. The positive effect was seen in the increase in the number of addressed and persuaded individuals belonging to the target audience, as well as in the increase in revenues. Several opted for other options, in which they had the opportunity to provide their own response, such as the emergence of new business partners, increased commitment within the organization, easier recruitment, and increased brand awareness. We continued to place great emphasis on the future of the SME sector in question, in terms of whether there are plans to expand our presence in social media. Unexpected results were obtained, as $56.7 \%$ answered in the negative and $43.3 \%$ answered in the affirmative. The following questions concerned only those companies that answered yes. Of the 253 companies selected, 149 would be willing to spend more capital on this. In their view, the most obvious solution is to appear on new social platforms, followed by the launch of various media campaigns. As a next step we provides the reader with a comprehensive picture of how businesses that want to take the opportunity to expand their presence on social media want to do so. It can be clearly stated that in the case of micro-enterprises the involvement of influencers and youtubers, in the case of small enterprises the involvement of external companies specializing in social media, and in the case of medium-sized enterprises the involvement of well-known persons is the priority.By comparison, in both regions studied, the number of enterprises with 0-9 employees is the highest, and as mentioned earlier, Facebook proved to be the most frequently used social platform. The summary also shows that, regardless of the size of the business, the provision of information is a priority for all of them. In most cases, the appearance on each platform has made a positive difference in the lives of the companies that take advantage of the opportunities that come with it, but there are no plans to expand this presence outside the medium-sized companies of the Central Transdanubia region and small businesses in the Western Transdanubia region. However, their goal is to launch media campaigns using sponsored ads with more capital. The majority of our respondents have been in social media for 1-5 years in both regions, which, based on their feedback, plays an important role in their lives.

\subsection{Hypothesis testing}

After the preparation of the theoretical part of our dissertation, the next indispensable part of our research plan was the setting up of the hypotheses and the examination of their correctness. The hypotheses we set up were formulated in a deductive way, the meaning of which suggests that we started from theoretical theorems and formulated our statements for the practical application of these assumptions. Based on the topic under study, five hypotheses were formulated, which are the following:

1. The active presence of small and medium-sized enterprises in social media has an impact on the company's marketing activities.

For the first hypothesis, considering Pearson's Chi-square test, it can be concluded that the two variables are significant because the significance value is less than 0.05 , which is illustrated in Table 2. Based on this, it can be said that there is a correlation between the two examined elements, i.e. in this case we reject the null hypothesis and the alternative hypothesis comes into force. From the value of Fi it can be concluded that the relationship between the two variables is one-way, and based on Cramer's V and Contingency coefficients it can be said that there is a stronger than average positive positive relationship between the variables. In ordinary language, it can be stated that the more active the 
company is on social media platforms, the greater the impact of this activity on the company's marketing strategy, ie, it places more emphasis on advertising, which increases revenue and increases the number of target audiences.Based on this, it can be said that the more significant a company is present on social media platforms, the greater the share of this activity among its marketing activities.

Table 2: Chi-square tests and symmertric measurements for Hypothesis 1.

\begin{tabular}{|c|c|c|c|c|c|}
\hline & & $\begin{array}{l}\text { Chi-square } \\
\text { rehearsals }\end{array}$ & & & \\
\hline Statistics & Value & df & $\begin{array}{l}\text { Asszimp. szig. (2- } \\
\text { tailed) }\end{array}$ & & \\
\hline $\begin{array}{l}\text { Pearson's } \\
\text { Chi square }\end{array}$ & 697,45 & 10 &, 000 & & \\
\hline $\begin{array}{l}\text { Likelihood } \\
\text { rate }\end{array}$ & 10,98 & 10 &, 000 & & \\
\hline \multirow[t]{2}{*}{$\begin{array}{l}\text { N/number } \\
\text { of valid } \\
\text { cases }\end{array}$} & 588 & & & & \\
\hline & & $\begin{array}{l}\text { Symmetrical } \\
\text { measurements }\end{array}$ & & & \\
\hline Category & Statistics & Value & $\begin{array}{l}\text { Aszimp.sztd.mist } \\
\text { ake }\end{array}$ & $\begin{array}{l}\text { Appr } \\
\text { oxima } \\
\text { te } T .\end{array}$ & $\begin{array}{l}\text { Appro } \\
\text { ximate } \\
\text { szig. }\end{array}$ \\
\hline \multirow[t]{3}{*}{$\begin{array}{l}\text { Nominal- } \\
\text { nominal }\end{array}$} & Phi & 1,09 & & & \\
\hline & Cramer's V &, 77 & & & \\
\hline & $\begin{array}{l}\text { Contingency } \\
\text { coefficient }\end{array}$ &, 74 & & & \\
\hline $\begin{array}{l}\text { N/number } \\
\text { of valid } \\
\text { cases }\end{array}$ & & 588 & & & \\
\hline
\end{tabular}

The questionnaire for the research shows that the majority of the small and public enterprise sector in the regions studied $(70 \%)$ is present on a social media platform, however, the remaining $30 \%$ still do not have the opportunity to take advantage of social media. gave opportunities. In our opinion, the reason for this is that they are afraid of change, do not want to innovate, are satisfied with old, proven methods, and are unaware of the benefits provided by social media. For them, the authors suggest that they take advantage of these opportunities. Make the first impression in the hands of the business. 
You can achieve this by creating a website, the amount of which is HUF 100,000 if it is done by an external company. . By moving to social platforms, which are today's dominant marketing communication tools, companies can share relevant articles, photos, videos, thereby maintaining contact with individual consumers.Having an online presence makes your business visible, makes your target audience easy to find, communicates with potential customers, and provides up-to-date information about changing consumer needs. Internet advertising contributes greatly to the growth of a company, but for this they need to constantly analyze the results, which they need to use. It is often heard that advertising is expensive, but in our opinion, advertising and online advertising are even more expensive in the long run, and that is nothing if the organization does not advertise. For them, the cost of advertising placement is about 150,000 HUF per month. In order to achieve continuous improvement, they need to set more and more goals. We also recommend companies to use the platforms on which they have the largest target audience. For young people, we recommend using Instagram. However, Linkedin is best suited for creating professionally relevant content.The authors 'critical remark extends to the fact that the SME sector employs only a very small percentage of individual / individuals / external companies to ensure a presence in social media. If they don't want to outsource this task, they have three options: educating, training their own employee, hiring a new employee, or hiring young, ambitious trainees with up-to-date information in the world of social media. In our opinion, this is essential, as the employment of a specialist specializing in this task would greatly contribute to increasing efficiency and speeding up the process. Based on payment data, today the salary of these professionals is around 200,000 HUF.Among the critical remarks, it is worth mentioning that, based on data collection, most companies do not monitor the presence of their competitors on social media at all. This is a problem because it often happens that a business could learn from the mistakes made by the competition, or even from their successes. In addition, if they get to know them well, the organization can get a comprehensive picture of what can give it its uniqueness, not to mention that the competitor encourages it to perform better day by day, and in terms of budget, this step does not involve capital expenditure. With regard to feedback from the target audience, we recommend that feedback be taken into account and used in all cases, as they need to adapt to ever-changing consumer needs if they want to be present in the market, and this step contributes to efficiency. takes into account and uses the suggestions, in the long run it will also have the opportunity to increase the existing consumer base. The authors concluded that businesses are not fully satisfied with the benefits of being present on social media platforms because they do not spend a sufficient percentage of their marketing costs or marketing activities on this factor. As a result, most of them believe that no level of change is taking place since they have been present in the online space. This short-term thinking suggests that most of them will have a negative opinion and thus will not reap the benefits, returning to the marketing and advertising tools previously used. nearly $50 \%$ of respondents do not plan to expand their presence on social media. We recommend that they also appear on other social platforms and, in terms of implementation, involve so-called influencers which are a great help, for example, in launching a targeted media campaign.

\section{Conclusions}

The main goal of our dissertation was to give the reader an insight into the role of social media in the life of small and medium-sized enterprises through the two regions of Hungary. As a first step, we described the exact definition of social media with the help of domestic and international literature, and then we examined its formation and development path in an international context. We have illustrated all this through the development of the Web. Our dissertation also covers when and how social media appeared in Hungary. It is 
important to mention that two social platforms have played a leading role in Hungary, iWiW and myVIP. One of the most well-known websites today, Facebook, was launched in 2007 , one of the cornerstones of which was baratikor.com. As a next step, we put a lot of emphasis on introducing the most common social media, including Facebook, Twitter, a social mini-blog, Instagram for sharing creative photos, and Linkedin, which is responsible for the emergence of professional life paths on social media platforms. After reviewing the possibilities, our dissertation examined the importance of social media in the small and medium-sized enterprise sector. In this subsection, we provide help and information to the managers of individual companies on why it is essential to be present on the mentioned platforms in today's world, be it small, medium and large companies. We have dedicated a separate subchapter to reviewing the most significant communication tool, social media, nowadays, during which we examined the market position of the most popular social platforms. In addition, it is important to highlight that the trends present in social media are constantly changing, which can be said to be the only thing in the world of the internet that is constant. In addition, we examined the situation in Hungary on the basis of research conducted by the NRC and the NMHH. Turning to the practical part of our dissertation, the focus is on the examination of two regions of Hungary.The territorial, social and economic situation of the Central Transdanubia and the Western Transdanubia region was presented, which shows a kind of comprehensive picture of the location of these areas in Hungary from the point of view of small and medium-sized enterprises. As the next step of our research, we analyzed the data of our questionnaire query. Of the nearly 3,000 questionnaires sent out, which contained 27 questions, 591 responses were received from the two regions surveyed. Subsequently, the authors formulated five hypotheses on the topic, the validity of which was processed with the help of the PSPP program. The formulated assumptions were evaluated using descriptive statistical tools.For the study, we used a cross-tabulation analysis in which the Pearsons Chi-square helped to establish the validity of the hypotheses. In several cases, the authors supplemented the research with symmetric indicators (Fi, Cramer's V and Contingency coefficients), which provided a comprehensive picture of the strength of the correlations between the variables. In the case of the hypotheses, we thought to discover a relationship between four pieces, while in the case of one piece there was no correlation. This means that the null hypothesis was rejected in four cases and accepted in one case. In the chapter entitled Conclusion, the reader gets an insight into the well-founded conclusions of the authors, as well as their suggestions, critiques and opinions based on them.It is also important to mention future research directions related to the topic under study, as the current state due to the coronavirus is expected to have a major impact on the future situation. It can be said about Hungary that webshops operate freely and more and more companies are starting to apply this kind of strategy, in which it is of great help to them that courier services deliver orders without any problems. In today's world, the consumer hears from all communication channels to stay at home! But how does a 21 st century customer react to this? Due to the restrictions currently in place, of course, you place orders online. However, not only the consumer but also the businesses need to adapt to this sudden change! In each case, demand will determine supply and in the current situation, demand for online orders will increase greatly.

\section{References}

1. Dr. I. Eszes, Digitális gazdaság. Nemzeti Tankönyvkiadó RT (Budapest),376. ISBN 978-963-19-7139-2 (2011) 
2. F. Novák. A közösségi média megjelenése, üzleti- és marketing szintű lehetőségei: szakdolgozat. Budapesti Gazdasági Főiskola. 11. (2010)

3. ThePitch. Facebook története. Retrieved from https://thepitch.hu/online-marketingszotar/facebook-tortenete/ (2018)

4. S. Kith. 53 Incredible Facebook Statistics and Facts. Retrieved from https://www.brandwatch.com/blog/facebook-statistics/ (2019)

5. E. Balla. Kulisszatitkok a Twitter alapításáról és müködéséről. Retrieved from http://valasz.hu/uzlet/kulisszatitkok-a-twitter-alapitasarol-es-mukodeserol-76862 (2014)

6. Instagram blog. Az Instagram története. Retrieved from https://instagram.blog.hu/2018/02/10/az_instagram_tortenete (2018)

7. Sz. Szatmári. A legfontosabb Instagram ${ }^{-}$statisztikák. Retrieved from https://marketingprofesszorok.hu/instagram-statisztika-2019.html (2019)

8. D. Csoma. Adatok a Twitterről és a Linkedlnről, amit sosem mertél megkérdezni. Retrieved from https://kozossegi-mediamindenkinek.blog.hu/2019/03/02/adatok_a_twitterrol_es_a_linkedinrol_amit_sosem_ mertel_megkerdezni (2019)

9. S. Gyöngyösi. A hétvégén lett 10 éves a Linkedln. Retrieved from https://marketingmorzsak.hu/a-hetvegen-lett-10-eves-a-linkedin/ (2013)

10. S. Keran. The Importance of Social Media in Business. Retrieved from https://www.lyfemarketing.com/blog/importance-social-media-business/ (2019)

11. Ryckposter.A közösségi média ereje. Retrieved from https://www.ryckposter.hu/akozossegi-media-ereje/

12. H. Lőcsei Ph.D., B. Bublik, A. Nyeste. Magyarország régióinak társadalmi-gazdasági profilja.Gazdaság- és Vállalkozáskutató Intézet. 142. (2013) 